\title{
The Experiences in Close Relationships-Relationship Structures Questionnaire: A Method for Assessing Attachment Orientations Across Relationships
}

\author{
R. Chris Fraley, Marie E. Heffernan, and \\ Amanda M. Vicary \\ University of Illinois at Urbana-Champaign
}

\author{
Claudia Chloe Brumbaugh \\ Queens College
}

\begin{abstract}
Most research on adult attachment is based on the assumption that working models are relatively general and trait-like. Recent research, however, suggests that people develop attachment representations that are relationship-specific, leading people to hold distinct working models in different relationships. The authors report a measure, the Relationship Structures questionnaire of the Experiences in Close Relationships-Revised (ECR-RS; R. C. Fraley, N. G. Waller, \& K. A. Brennan, 2000), that is designed to assess attachment dimensions in multiple contexts. Based on a sample of over 21,000 individuals studied online, it is shown that ECR-RS scores are reliable and have a structure similar to those produced by other measures. In Study $2(N=388)$, it is shown that relationship-specific measures of attachment generally predict intra- and interpersonal outcomes better than broader attachment measures but that broader measures predict personality traits better than relationship-specific measures. Moreover, it is demonstrated that differentiation in working models is not related to psychological outcomes independently of mean levels of security.
\end{abstract}

Keywords: adult attachment, close relationships, measurement, relationships, personality

Over the last 20 years Bowlby's (1969) attachment theory has become one of the leading theoretical frameworks for the study of emotion regulation, personality development, and interpersonal relationships (see Cassidy \& Shaver, 2008, for a review). One of the core assumptions of adult attachment theory is that people construct mental representations, or working models, of the self and significant others based on their interpersonal experiences. These representations are believed to play an important role in the way people interpret and understand their social worlds. As such, assessing the security of working models is crucial for understanding personality dynamics, emotions, and interpersonal relationships.

Attachment researchers in the social-personality field have traditionally conceptualized working models in a trait-like fashion. In other words, they have assumed that these representations are relatively influential across a wide array of relational contexts, including relationships with parents, friends, and romantic partners. In accordance, self-report questionnaires for assessing the quality of people's working models often instruct participants to evaluate their experiences in close relationships in general, rather than instructing participants to focus on a specific relationship

This article was published Online First March 28, 2011.

R. Chris Fraley, Marie E. Heffernan, and Amanda M. Vicary, Department of Psychology, University of Illinois, Urbana-Champagne; Claudia Chloe Brumbaugh, Department of Psychology, Queens College.

This research was supported by National Science Foundation Grant 0443783 to R. Chris Fraley.

Correspondence concerning this article should be addressed to R. Chris Fraley, Department of Psychology, University of Illinois, 603 East Daniel St., Champaign, IL 61820. E-mail: rcfraley@illinois.edu (e.g., Collins \& Read, 1990; Hazan \& Shaver, 1987). The common practice of relying exclusively on general or global measures of attachment, however, has been criticized (Baldwin, Keelan, Fehr, Enns, \& Koh-Rangarojoo, 1996; Cook, 2000; La Guardia, Ryan, Couchman, \& Deci, 2000). Baldwin et al. (1996), for example, demonstrated that there is considerable within-person variability in the expectations and beliefs that people hold about significant others in their lives. A person may consider his or her spouse to be warm, affectionate, and responsive, for example, yet, because of a different relational history, simultaneously view his or her mother as being cold, rejecting, and aloof. The fact that substantial withinperson variation exists in the way people relate to important others in their lives raises a number of questions about whether common methods for assessing self-reported attachment style are adequate.

One of the goals of this article is to present a questionnaire that was designed to assess individual differences in attachment within and across a variety of relational contexts. More precisely, this questionnaire was designed to address four methodological problems that exist in contemporary attachment assessment and research. First, many self-report measures of adult attachment are referentially ambiguous. A prototypical attachment questionnaire instructs participants to think back upon their relationships with close others, without necessarily specifying whether those close others are romantic partners, parents, friends, etc. Moreover, even when the domain is more precisely specified (e.g., romantic relationships), participants in some studies might be instructed to reference a specific relationship (e.g., Figueiredo et al., 2008), whereas participants in other studies might be instructed to reference romantic relationships more generally (e.g., Zayas, Shoda, Mischel, Osterhout, \& Takahashi, 2009). A self-report measure of attachment ideally should specify unambiguously what kind of relationship is being assessed. 
Second, many measures of adult attachment, if they are not referentially ambiguous in the way described above, are potentially too narrow. For example, most self-report measures are designed to assess romantic attachment, and, accordingly, many of the questionnaire items are written with romantic relationships in mind (e.g., "When my partner is out of sight, I worry that he or she might become interested in someone else"). The fact that some of the items are specific to romantic relationships can lead to problems if an investigator wishes to use the same basic item pool to assess attachment in nonromantic relationships (e.g., parents, teachers, therapists, friends). One solution to this problem is to use one kind of questionnaire to assess romantic attachment representations, for example, and another questionnaire to assess parental attachment representations. This solution, however, is less than ideal because questionnaires designed to assess attachment in different relationships do not always use a common item pool. Indeed, sometimes they do not assess the same constructs. For example, one of the most commonly used self-report measures of security in parental relationships is the Inventory of Parent and Peer Attachment (IPPA; Armsden \& Greenberg, 1987). The IPPA is used to score participants on three dimensions: degree of mutual trust, quality of communication, and degree of anger and alienation. Commonly used self-report measures of romantic attachment, however, are used to scale people on attachment-related anxiety and avoidance. Although the scales used in these different inventories have obvious conceptual and empirical commonalities (see Brennan, Clark, \& Shaver, 1998), they were not designed to capture the same constructs and, as such, cannot be compared as if they shared a common metric. An ideal assessment tool would use the same kinds of items and scales to assess attachment security in different relationships, making comparisons across relationships more meaningful.

A third problem is that contemporary self-report measures are relatively long. For example, the Experiences in Close Relationships (ECR; Brennan et al., 1998) and the ECR-Revised (ECR-R; Fraley, Waller, \& Brennan, 2000), two of the most commonly used measures of adult attachment, both contain 18 items designed to assess attachment-related anxiety and 18 items to assess attachment-related avoidance (36 items total). If a researcher was interested in assessing security across multiple relationship contexts, the number of items needed for the assessment would multiply accordingly and become potentially unwieldy. Given that there is a sizable amount of redundancy among some attachment items, it is possible that a shorter set of items could be used without sacrificing too much measurement precision (see Lo et al., 2009, and Wei, Russell, Mallinckrodt, \& Vogel, 2007, for a similar argument). An ideal measure would allow attachment to be assessed across multiple relationships without placing too much of a burden (in terms of the number of items rated) on research participants.

A final concern is that contemporary measures of attachment do not allow within-person variation to be assessed across relational contexts. As several researchers have observed, the correlation between security assessed in different domains (e.g., parental, romantic) is imperfect (see Baldwin et al., 1996; Brumbaugh \& Fraley, 2007; Buist, Reitz, \& Dekovíc, 2008; Cook, 2000; Klohnen, Weller, Luo, \& Choe, 2005). This implies that there is some degree of variability in the homogeneity of people's working models. Some people might have relatively homogeneous attach- ment representations; they might be highly secure, for example, in a variety of relationship contexts. Other people, however, might exhibit a greater degree of differentiation (see Donahue, Robins, Roberts, \& John, 1993). If someone has a history of being rejected by his or her parents but is currently involved in a romantic relationship with a supportive and responsive partner, it is possible that the working models that the person will hold for these different kinds of relationships will not be identical. Such a person might be highly secure with his or her romantic partner but relatively insecure with respect to his or her parents. Unfortunately, it is not possible to assess differentiation without assessing working models across different relationship contexts. Moreover, contemporary assessment methods do not permit a unified or common means for doing so, leaving questions about how differentiation in working models might affect psychological functioning unanswered.

To address these four concerns, we explored a derivation of the ECR-R questionnaire that was designed to assess attachmentrelated anxiety and avoidance in four kinds of relationships: relationships with mother, father, romantic partners, and friends. The modified questionnaire, which we refer to as the Relationships Structure questionnaire, or the ECR-RS, contains nine items that assess attachment in each of those four domains, producing 36 items total. In Study 1, we report some of the basic psychometric properties of the ECR-RS and provide descriptive summaries of the scales based on a sample of over 21,000 people who vary in age, sex, ethnicity, and country of residence. In Study 2, we investigate the convergent and discriminant validity of the ECR-RS in a sample of 388 individuals in dating or marital relationships. We demonstrate that (a) the ECR-RS measures of romantic attachment are associated with basic aspects of relationship functioning (e.g., satisfaction, commitment, investment); (b) taking context into account allows certain relationship outcomes to be better understood; (c) the subscales of the ECR-RS are just as reliable as those based on longer inventories (e.g., the ECR-R); (d) the ECR-RS scales, although exhibiting the same pattern of associations with measures of the Big Five personality traits as the ECR-R, are less strongly correlated with basic personality traits than those from the ECR-R. We also examine the association between the differentiation in working models across relational contexts and psychological functioning.

We note from the outset that our goal is not to provide an "alternative" method for assessing adult attachment or to introduce a new attachment measure per se. One challenge for investigators and practitioners who are interested in assessing adult attachment is that there is a plethora of self-report instruments to choose from. In fact, this situation has become more problematic in recent years because, despite the fact that there is a growing interest in assessing attachment in a contextual fashion, there is no common method for doing so. Indeed, the studies that have been published in the literature to date each use different methods and instruction sets, different self-report questionnaires, and, in some cases, different conceptual models of individual differences in attachment. We believe that some degree of methodological continuity is useful for building a cumulative knowledge base about attachment dynamics. As such, we hope to demonstrate how an already existing and widely used measure (i.e., the ECR-R) can be adapted to facilitate the contextualized assessment of attachment styles. We hope that people who are interested in assessing attachment in a context- 
specific way will find the ECR-RS a useful measure for their purposes.

\section{Study 1}

\section{Method}

Participants. Data from over 23,000 people were collected through a website designed "to assess your attachment style in different relationships." The study was hosted on the first author's website, which contains a variety of web studies and demonstrations regarding personality, attachment, and close relationships. The site can be found via web searches for a variety of key words relevant to personality and relationships and receives approximately 100 to 200 visitors a day (although not all visitors participate in each study and/or exercise posted on the website). (For an in-depth comparison of web-based samples and more traditional samples in psychological research, please see Gosling, Vazire, Srivastava, \& John, 2004.)

Although data were originally collected from over 36,000 participants, for the purposes of the present article, we focused on a subsample of 21,838 respondents who reported being involved in exclusive dating or marital relationships. The primary reason for this focus is that most research on adult attachment in social and clinical psychology has highlighted attachment in romantic relationships. Moreover, because we were interested in assessing attachment across distinct relationships, we wanted to ensure that we could compare security across specific relational domains (e.g., mother, father, romantic partner, and friendships) in a way that was meaningful to each respondent. The sample was composed primarily of women $(81.5 \%)$. The average age of participants was 31.35 years $(S D=11.28)$. The majority of participants were from the United States $(n=14,781)$, with the remainder of the sample participating from Great Britain $(n=1,852)$, Canada $(n=1,232)$, or elsewhere. The majority of participants were White $(70.5 \%)$, followed by $6.6 \%$ Black, and $4.2 \%$ Latino.

Materials and procedure. Participants rated an initial pool of 10 items designed to assess their attachment orientation across four kinds of intimate relationships (i.e., relationships with mother, father, romantic partners, and best friends). The same 10 items were used for each domain, yielding 40 items total. For each item, participants were asked to indicate on a 7-point scale the extent to which they agreed or disagreed with the item $(1=$ strongly disagree $;$ = strongly agree $)$. The items were selected in modified form from the ECR-R, a widely used attachment inventory designed to assess the two fundamental dimensions underlying attachment patterns: anxiety and avoidance (Fraley et al., 2000). The anxiety dimension represents the extent to which people tend to worry about attachment-related concerns, such as the availability and responsiveness of an attachment figure. The avoidance dimension represents the extent to which people are uncomfortable opening up to others and depending on them. Prototypically secure people tend to score low on both dimensions.

The ECR-R was developed based on an examination of an item pool of 323 items - items based on previously existing inventories as well as the authors' attempts to capture item content that was not adequately represented in those inventories (see also Brennan et al., 1998). Using a combination of factor analytic methods and graded/polychotomous item response theory models, the authors selected items for each dimension based on estimated item discrimination parameters (comparable to reliability or alpha) and item difficulty parameters (reflecting the threshold needed on the latent dimension for respondents to endorse and item), with specific attention to representing a wide array of difficulty values. For the purpose of selecting items for the ECR-RS, we identified items from the ECR-R that had good item discrimination values but excluded items if they (a) were worded in a manner that was explicitly focused on romantic relationships or (b) had difficulty values that were too redundant with other items. The items we selected are listed in Table 1.

Factor analyses. To examine the factor structure of the ECR-RS items, we conducted an exploratory factor analysis using principal axis factoring, followed by varimax rotation, separately for the 10 attachment items for each of the four relational domains. The purpose of this analysis was to determine whether the item responses had a two-factor structure similar to that commonly found with other instruments. The first three eigenvalues from each analysis were as follows: $5.79,1.58$, and 0.76 for the maternal domain; 5.84, 1.49, and 0.91 for the paternal domain; 5.18, 1.80, and 0.89 for the romantic domain; and 5.24, 1.70, 0.92 for the friend domain. In each of the four relational domains, at least two factors were necessary to represent the data. The first two factors accounted for over $69 \%$ of the cumulative variance in each domain.

Table 1 shows the factor loadings for the items in each domain, using a two-factor solution. In each domain, there were clear avoidance and anxiety factors. The items that were designed to assess avoidance tended to have moderate to strong loadings on the first factor. The items that were designed to assess anxiety tended to have strong loadings on the second factor. One noteworthy result of these analyses is that the item "I don't fully trust this person," originally selected to be a potential measure of anxiety, tended to load relatively moderately on both factors. As such, we decided to exclude it in our subsequent analyses because it is not a "clean" measure of anxiety per se. Another result of interest is that some of the items had moderate cross-loadings. However because the specific items that had moderate cross-loadings in one domain did not necessarily have moderate cross-loadings in other relationship domains, we did not exclude these items from subsequent analyses.

Composite scores. On the basis of these analyses, we created unit-weighted composite measures in each relational domain of avoidance based on Items 1-6 and anxiety based on Items 7-9 (see Table 1). Items 5 and 6 in Table 1 were reverse keyed. As mentioned previously, we excluded Item 10 because of its relatively high cross-loadings across domains. We focus on these composites in the analyses that follow.

The means, standard deviations, skewness, Cronbach's alphas, and intercorrelations among the scores are reported in Table 2. There are several features of these data that warrant discussion. First, the means are relatively low, suggesting that the average person is relatively secure (i.e., low on attachment-related anxiety and avoidance). This result is similar to what is found using longer and more general measures of attachment (see Study 2). In fact there is a noteworthy skewness in the items and the scales, as reported in Table 2, reflecting a high distribution of people on the low end of the anxiety and avoidance dimensions in each relational domain. The primary exception to this general trend is that avoid- 
Table 1

Factor Loadings for ECR-RS Items Rated With Respect to Mother, Father, Romantic, and Friend Domains

\begin{tabular}{|c|c|c|c|c|c|c|c|c|}
\hline \multirow[b]{2}{*}{ Item } & \multicolumn{2}{|c|}{ Mother } & \multicolumn{2}{|c|}{ Father } & \multicolumn{2}{|c|}{ Partner } & \multicolumn{2}{|c|}{ Friend } \\
\hline & Avoid & Anxiety & Avoid & Anxiety & Avoid & Anxiety & Avoid & Anxiety \\
\hline $\begin{array}{l}\text { 1. I usually discuss my problems and concerns } \\
\text { with this person. }\end{array}$ & .91 & -.16 & 90 & -18 & 90 & -.10 & 90 & -12 \\
\hline 2. I talk things over with this person. & .89 & -.20 & 88 & -.21 & .87 & -.12 & .88 & -.14 \\
\hline 3. It helps to turn to this person in times of need. & .84 & -.29 & .80 & -.33 & .79 & -.20 & .82 & -.21 \\
\hline 4. I find it easy to depend on this person. & .68 & -.42 & .66 & -.46 & .66 & -.35 & .66 & -.33 \\
\hline $\begin{array}{l}\text { 5. I prefer not to show this person how I feel } \\
\text { deep down. }\end{array}$ & -.62 & .25 & -.60 & .27 & -.56 & .25 & -.52 & .36 \\
\hline $\begin{array}{l}\text { 6. I don't feel comfortable opening up to this } \\
\text { person. }\end{array}$ & -.66 & .22 & -.59 & .23 & -.54 & .21 & -.47 & .28 \\
\hline 7. I'm afraid this person may abandon me. & -.18 & .81 & -.22 & .84 & -.14 & .85 & -.16 & .85 \\
\hline $\begin{array}{l}\text { 8. I worry that this person won't care about me } \\
\text { as much as I care about him or her. } \\
\text { 9. I often worry that this person doesn't really }\end{array}$ & -.18 & .85 & -.21 & .84 & -.15 & .88 & -.16 & .86 \\
\hline care for me. & -.32 & .79 & -.31 & .81 & -.29 & .83 & -.29 & .82 \\
\hline 10. I don't fully trust this person. & -.51 & .59 & -.49 & .62 & -.46 & .57 & -.43 & .57 \\
\hline
\end{tabular}

Note. $\quad$ ECR-RS = Relationship Structures questionnaire of the Experiences in Close Relationships—Revised (Fraley, Waller, \& Brennan, 2000). Loadings greater than I.40I are highlighted in bold typeface. Instructions for the ECR-RS were printed separately for each relationship domain: "Please answer the following 10 questions about your mother or a mother-like figure," "Please answer the following 10 questions about your father or a father-like figure," "Please answer the following 10 questions about your dating or marital partner," "Please answer the following 10 questions about your best friend." Item 10 was not used in the final version of the ECR-RS but is reported here for descriptive purposes.

ance with father tended to have an average score closer to the mid point of the scale and, accordingly, a much more normal distribution of scores.

Second, although the ECR-RS scales are based on fewer items than have been used in some of the more recent multi-item attachment inventories (e.g., the ECR and ECR-R), the alpha reliability estimates of the scores are highly comparable to those derived from longer scales. For example, the lowest alpha reported in Table 2 is .85 , whereas the alphas reported by researchers who use longer measures, such as the ECR (Brennan et al., 1998) or the
ECR-R (Fraley et al., 2000) are typically around .91. It is possible that the specificity that is added by contextualizing the targets helps to reduce some of the measurement noise that exists when the targets are less precisely specified, thereby allowing the use of fewer items without sacrificing precision.

Third, in parallel to the observations of other researchers (e.g., Baldwin et al., 1996; Klohnen et al., 2005), the correlations among the attachment dimensions in different domains are positive, but not particularly strong. For example, people who report avoidant attachment orientations with their mothers are more likely to report

Table 2

Study 1 Summary of Correlations, Means, Standard Deviations, and Skewness for Relationship Structures Anxiety and Avoidance Scores in Each Relational Domain

\begin{tabular}{|c|c|c|c|c|c|c|c|c|c|c|}
\hline \multirow[b]{2}{*}{ Variable } & \multicolumn{4}{|c|}{ Anxiety } & \multicolumn{4}{|c|}{ Avoidance } & \multicolumn{2}{|c|}{ Global } \\
\hline & Mother & Father & Partner & Friend & Mother & Father & Partner & Friend & Anxiety & Avoidance \\
\hline \multicolumn{11}{|l|}{ Anxiety } \\
\hline Mother & .88 & & & & & & & & & \\
\hline Father & .41 & .90 & & & & & & & & \\
\hline Partner & .24 & .24 & .91 & & & & & & & \\
\hline Friend & .29 & .28 & .25 & .90 & & & & & & \\
\hline \multicolumn{11}{|l|}{ Avoidance } \\
\hline Mother & .50 & .18 & .12 & .17 & .92 & & & & & \\
\hline Father & .17 & .55 & .15 & .17 & .29 & .90 & & & & \\
\hline Partner & .15 & .12 & .44 & .13 & .17 & .12 & .87 & & & \\
\hline Friend & .14 & .11 & .09 & .48 & .29 & .16 & .14 & .88 & & \\
\hline \multicolumn{11}{|l|}{ Global } \\
\hline Anxiety & .70 & .72 & .67 & .64 & .35 & .39 & .32 & .28 & .85 & \\
\hline Avoidance & .41 & .41 & .30 & .36 & .72 & .69 & .52 & .55 & .54 & .88 \\
\hline$M$ & 2.11 & 2.42 & 3.25 & 2.34 & 3.57 & 4.20 & 2.47 & 2.47 & 2.53 & 3.18 \\
\hline$S D$ & 1.62 & 1.82 & 1.98 & 1.53 & 1.76 & 1.74 & 1.31 & 1.27 & 1.19 & 0.96 \\
\hline Skewness & 1.48 & 1.16 & 0.45 & 1.14 & 0.31 & -0.01 & 0.94 & 0.93 & 0.85 & 0.22 \\
\hline
\end{tabular}

Note. Cronbach's alphas are on the diagonal in italics. 
avoidance in their romantic relationships but only to a modest degree $(r=.17)$. This suggests that although there is a common "theme" that tends to cut across people's relationships, there is also quite a bit of within-person variation, such that people who are secure with their parents may be insecure with their romantic partners. Overall, people reported the greatest amount of similarity in the way they related to their mothers and fathers $(r=.41$ for anxiety with mother and father) and the least amount of similarity between fathers and partners $(r=.12$ for avoidance with father and partner). This finding is similar to that reported by Klohnen et al. (2005), namely that peer representations (e.g., partner and friend models) are more similar to one another than they are to parental representations (e.g., models of mother and father) and vice versa.

On the basis of Overall, Fletcher, and Friesen's (2003) factor analytic results, we also created composites for avoidance and anxiety based on all of the items across each of the four relational contexts as a way of representing a more "global" or generalized attachment style. As can be seen in Table 2, the reliabilities of these composite scores were also high (.85 for anxiety and .88 for avoidance). Thus, although there are only small to moderate correlations across domains for each attachment dimension, a composite designed to capture the variance that is common to those domains is relatively reliable.

We also examined sex differences in the scales (see Table 3). For the most part, men and women differed in their anxiety and avoidance ratings across the various scales. In general, men tended to report less anxiety and more avoidance than women across domains. This is consistent with findings by Schmitt and his colleagues (e.g., Schmitt \& the International Sexuality Description Project, 2003).

Finally, it is noteworthy that the correlations between anxiety and avoidance are relatively high in each relational domain. People who tend to be more avoidant in their relationships with their mothers, for example, also report being more worried about their mother's availability and responsiveness $(r=.50)$. These correlations are worth mentioning because previous research using longer and less relationship-specific inventories has reported that the two attachment dimensions are only weakly correlated, around .13, for example (see Brennan et al., 1998). We discuss some possible reasons for this in the General Discussion.

\section{Study 2}

The objective of the second study was to determine the association between the contextualized ECR-RS measures of attachment and a more commonly used and less contextualized self-report measure of attachment, the ECR-R (Fraley et al., 2000). We also wanted to determine whether the ECR-RS was able to predict relational and personal outcomes with a similar degree of precision as the ECR-R and whether there was any value in assessing attachment across multiple relational domains. Specifically, we examined the extent to which the differentiation of people's working models (i.e., the heterogeneity vs. the homogeneity of working models) was related to various outcomes of intra- and interpersonal significance.

\section{Method}

Participants. Data from 388 people in dating or marital relationships were collected as part of a larger research study in our laboratory. The sample was composed primarily of women $(65 \%)$. The average age of participants was 22.59 years $(S D=$ 6.27). The average relationship length of participants' romantic relationships was 31.94 months $(S D=36.9)$. The majority of participants were Caucasian (72.2\%), followed by Chinese American $(8.5 \%)$ and Latino (4.1\%).

\section{Materials and procedure.}

Adult attachment. Participants rated the items from the ECR-RS questionnaire, again focusing separately on relationships with mother, father, partner, and best friend. Although we collected data for all $10 \mathrm{RS}$ items, based on the previous analyses, we omitted the 10th item in each subdomain from our scales. For the Anxiety scale, the alpha reliabilities for these four domains were $.84, .87, .83$, and .83 , respectively. For the Avoidance scale, the alpha reliabilities for the four domains were $.91, .92, .81$, and .85 , respectively. As before, we assessed general working models via the ECR-RS by averaging the items from each domain. The alpha for the global anxiety scores was .80, and the alpha for the global avoidance scores was .88. We also administered the ECR-R (Fraley et al., 2000) to assess avoidance and anxiety in a more standard, global fashion. The ECR-R contains 36 items and is designed to assess romantic attachment. The instructions were

Table 3

Study 1 Sex Differences

\begin{tabular}{lccrrr}
\hline Variable & $M(S D)$ for Men & $M(S D)$ for Women & \multicolumn{1}{c}{$t$} & $d f$ & Cohen's $d$ \\
\hline Anxiety & & & & & \\
$\quad$ Mother & $1.92(1.42)$ & $2.15(1.66)$ & 8.78 & $6,504.08$ & 0.15 \\
Father & $2.28(1.64)$ & $2.46(1.86)$ & 5.94 & $6,279.29$ & 0.10 \\
Partner & $3.05(1.90)$ & $3.29(1.99)$ & 7.31 & $5,976.40$ & 0.12 \\
$\quad$ Friend & $2.41(1.45)$ & $2.32(1.55)$ & -3.71 & $5,907.11$ & -0.06 \\
Avoidance & & & & & \\
$\quad$ Mother & $3.77(1.62)$ & $3.52(1.78)$ & -8.58 & $6,202.66$ & -0.15 \\
Father & $4.15(1.63)$ & $4.21(1.76)$ & 2.09 & $6,030.28$ & 0.04 \\
Partner & $2.56(1.28)$ & $2.44(1.32)$ & -4.98 & $5,900.97$ & -0.09 \\
Friend & $2.89(1.35)$ & $2.38(1.24)$ & -21.79 & $5,347.31$ & -0.39 \\
Global & & & & & \\
$\quad$ Anxiety & $2.42(1.11)$ & $2.56(1.21)$ & 6.84 & $6,175.43$ & 0.12 \\
Avoidance & $3.34(0.96)$ & $3.14(0.96)$ & -11.90 & $5,802.89$ & -0.21 \\
\hline
\end{tabular}

Note. All differences are significant at $p<.05$. Equal variances are not assumed for the $t$ tests. 
written to make the ECR-R items relevant to romantic relationships, but not to be exclusively about participants' current romantic relationship: "The statements below concern how you feel in emotionally intimate relationships. We are interested in how you generally experience relationships, not just in what is happening in your current relationship." The alpha reliabilities for the ECR-R anxiety and avoidance scores were .88 and .92 , respectively. The average ECR-R anxiety score in the sample was $2.85(S D=1.12)$; the average avoidance score was $2.34(S D=0.98)$. These means suggest that the average person in our sample was relatively secure. The correlation between the two ECR-R dimensions was .41.

Relationship functioning. Participants also completed the Investment Model Scale (IMS) as a means for assessing relationship quality and functioning (Rusbult, Martz, \& Agnew, 1998). The IMS assesses commitment, investment, satisfaction in a relationship, and the quality of alternatives. The alpha reliabilities for the scores in these domains in the present study were $.91, .70, .85$, and .79 , respectively. In the present study, participants were asked to rate these items with respect to their current relationship.

Intrapersonal functioning. The 9-item version of the Center for Epidemiologic Studies-Depression scale (CES-D) was used in the present sample to assess depressive symptoms (Kohout, Berkman, Evans, \& Cornoni-Huntley, 1993). This brief scale produces reliability and validity statistics that are comparable to those based on the full-scale version in previous research (Kohout et al., 1993). The alpha of the scores in the present sample was .90.

Big Five personality traits. The 44-item Big Five Inventory (John \& Srivastava, 1999) was used to asses individual differences in the Big Five personality traits: Extraversion, Agreeableness, Conscientiousness, Neuroticism, and Openness to Experience. The alpha reliabilities for these scores were $.90, .80, .82, .84$, and .81 , respectively.

\section{Results}

The means, standard deviations, skewness, Cronbach's alphas, and intercorrelations among the various ECR-RS scores are reported in Table 4. For the most part, these statistics were similar to those reported in Study 1. Table 5 reports the correlations between the ECR-R attachment dimensions and the ECR-RS dimensions. There are two points of interest in this table. First, on average, the ECR-R dimensions and the ECR-RS dimensions were positively but weakly correlated. Second, the two measures tended to be most strongly correlated in the romantic domain. ECR-anxiety correlated .66 with RS-romantic anxiety; ECR-R avoidance correlated .56 with RS-romantic avoidance. This is noteworthy because it suggests that the ECR-R, despite typically being used as a global measure of attachment, captures mostly variance that is relevant to the romantic domain.

We next examined the association between these two measures of attachment and various relational and intrapersonal outcomes. Table 5 reports these correlations. In general, ECR-RS anxiety and avoidance across most relational domains was related to relationship functioning. However, the associations were much more salient in the romantic domain. For example, RS avoidance in romantic relationships was negatively correlated with commitment ( $r=-.53)$, satisfaction $(r=-.49)$, and investment $(r=-.28)$ and positively correlated with the desirability of alternative partners $(r=.38)$. As expected, the ECR-R dimensions also correlated with these relational variables in similar ways. Highly anxious and avoidant people tended to be less committed, less satisfied, and less invested in their relationships, while also viewing alternative partners as more desirable. With one exception, the ECR-RS partner dimensions correlated just as strongly with the relational and intrapersonal outcomes as the ECR-R dimensions. The exception was that ECR-RS-partner avoidance correlated more strongly with commitment than did ECR-R avoidance $(z=-2.55, p<.05)$.

Table 4

Study 2 Summary of Correlations, Means, Standard Deviations, and Skewness for Relationship Structures Anxiety and Avoidance Scores in Each Relational Domain

\begin{tabular}{|c|c|c|c|c|c|c|c|c|c|c|}
\hline \multirow[b]{2}{*}{ Variable } & \multicolumn{4}{|c|}{ Anxiety } & \multicolumn{4}{|c|}{ Avoidance } & \multicolumn{2}{|c|}{ Global } \\
\hline & Mother & Father & Partner & Friend & Mother & Father & Partner & Friend & Anxiety & Avoidance \\
\hline \multicolumn{11}{|l|}{ Anxiety } \\
\hline Mother & .84 & & & & & & & & & \\
\hline Father & .44 & .87 & & & & & & & & \\
\hline Partner & .11 & .15 & .83 & & & & & & & \\
\hline Friend & .22 & .25 & .20 & .83 & & & & & & \\
\hline \multicolumn{11}{|l|}{ Avoidance } \\
\hline Mother & .51 & .23 & .11 & .17 & .91 & & & & & \\
\hline Father & .22 & .53 & .16 & .17 & .40 & .92 & & & & \\
\hline Partner & .06 & .12 & .38 & .13 & .12 & .13 & .81 & & & \\
\hline Friend & .10 & .21 & .12 & .47 & .25 & .26 & .18 & .85 & & \\
\hline \multicolumn{11}{|l|}{ Global } \\
\hline Anxiety & .64 & .70 & .60 & .65 & .40 & .42 & .30 & .36 & .80 & \\
\hline Avoidance & .39 & .46 & .25 & .39 & .75 & .77 & .41 & .59 & .57 & .88 \\
\hline$M$ & 1.48 & 1.61 & 1.92 & 1.89 & 2.94 & 3.55 & 1.65 & 2.26 & 1.73 & 2.60 \\
\hline$S D$ & 1.01 & 1.15 & 1.27 & 1.18 & 1.57 & 1.67 & 0.82 & 1.10 & 0.75 & 0.87 \\
\hline Skewness & 2.69 & 2.18 & 1.66 & 1.49 & 0.62 & 0.31 & 1.79 & 0.69 & 1.36 & 0.36 \\
\hline
\end{tabular}

Note. Cronbach's alphas are on the diagonal in italics. 
Table 5

Correlations Between Relationship Structures Anxiety and Avoidance, Rusbult's Investment Model Variables, and Depression

\begin{tabular}{|c|c|c|c|c|c|c|c|}
\hline \multirow[b]{2}{*}{ Scale } & \multicolumn{2}{|c|}{ ECR-R } & \multicolumn{4}{|c|}{ Rusbult's Investment Model } & \multirow[b]{2}{*}{ CES-D } \\
\hline & Anxiety & Avoidance & Commitment & Satisfaction & Alternatives & Investment & \\
\hline \multicolumn{8}{|l|}{ ECR-RS } \\
\hline \multicolumn{8}{|l|}{ Anxiety } \\
\hline Mother & .13 & .10 & .04 & .01 & -.04 & .07 & .20 \\
\hline Father & .10 & .18 & -.05 & -.09 & .02 & -.05 & .15 \\
\hline Partner & .66 & .31 & -.22 & -.37 & .21 & -.09 & .33 \\
\hline Friend & .27 & .16 & -.08 & -.12 & -.01 & .04 & .30 \\
\hline Global & .47 & .30 & -.13 & -.23 & .07 & -.02 & .39 \\
\hline \multicolumn{8}{|l|}{ Avoidance } \\
\hline Mother & .12 & .15 & .00 & -.05 & -.05 & .14 & .19 \\
\hline Father & .12 & .14 & .01 & -.09 & .04 & -.02 & .15 \\
\hline Partner & .31 & .56 & -.53 & -.49 & .38 & -.28 & .27 \\
\hline Friend & .13 & .13 & .00 & -.11 & -.09 & .09 & .11 \\
\hline Global & .23 & .31 & -.12 & -.22 & .06 & .02 & .25 \\
\hline \multicolumn{8}{|l|}{ ECR-R } \\
\hline Anxiety & - & .41 & -.21 & -.33 & .17 & -.04 & .40 \\
\hline Avoidance & .41 & - & -.43 & -.42 & .33 & -.30 & .28 \\
\hline
\end{tabular}

Note. ECR-R = Experiences in Close Relationships-Revised (Fraley, Waller, \& Brennan, 2000); CES-D = Center for Epidemiologic StudiesDepression scale (Kohout, Berkman, Evans, \& Cornoni-Huntley, 1993); ECR-RS = Relationship Structures questionnaire of the ECR-R. Correlations $>$ 1.091 are statistically significant.

The ECR-RS measures of anxiety and avoidance also correlated with measures of depressive symptoms. People who were more insecure (i.e., higher on anxiety or avoidance) in the four relationship domains tended to report a higher number of depressive symptoms. This was true for the ECR-R measures of anxiety and avoidance as well.

We also studied the association between the ECR-RS dimensions and measures of the Big Five personality traits. These correlations are reported in Table 6 . In general, the pattern of associations between the Big Five personality traits and the ECR-RS attachment dimensions is similar to what other investigators have reported using different measures of attachment (e.g., Noftle \& Shaver, 2006). Specifically, attachment-related anxiety tends to correlate with neuroticism and attachment-related avoidance tends to correlate negatively with agreeableness. One noteworthy feature of these data is that the ECR-R dimensions were more strongly correlated with the Big Five traits than the ECR-RS dimensions in the domains in which attachment and personality traits tend to correlate. For example, the correlation between ECR-R anxiety and neuroticism was .36, whereas the correlation between ECR-RS

Table 6

Correlations Between Relationship Structures Anxiety and Avoidance and the Big Five Personality Traits

\begin{tabular}{|c|c|c|c|c|c|}
\hline \multirow[b]{2}{*}{ Scale } & \multicolumn{5}{|c|}{ Big Five personality traits } \\
\hline & Extraversion & Agreeableness & Neuroticism & Conscientiousness & Openness \\
\hline \multicolumn{6}{|l|}{ ECR-RS } \\
\hline \multicolumn{6}{|l|}{ Anxiety } \\
\hline Mother & -.12 & -.11 & -.11 & -.12 & -.06 \\
\hline Father & -.08 & -.11 & .08 & -.13 & .00 \\
\hline Partner & -.13 & -.25 & .22 & -.20 & -.09 \\
\hline Friend & -.20 & -.25 & .24 & -.16 & -.07 \\
\hline Global & -.21 & -.28 & .26 & -.24 & -.08 \\
\hline \multicolumn{6}{|l|}{ Avoidance } \\
\hline Mother & -.21 & -.20 & .10 & -.20 & -.04 \\
\hline Father & -.14 & -.18 & .15 & -.14 & -.02 \\
\hline Partner & -.12 & -.28 & .08 & -.29 & .03 \\
\hline Friend & -.28 & -.23 & .10 & -.24 & .02 \\
\hline Global & -.28 & -.32 & .17 & -.30 & -.02 \\
\hline \multicolumn{6}{|l|}{ ECR-R } \\
\hline Anxiety & -.10 & -.28 & .36 & -.23 & -.05 \\
\hline Avoidance & -.12 & -.35 & .16 & -.22 & -.03 \\
\hline
\end{tabular}

Note. $\quad$ ECR-R $=$ Experiences in Close Relationships-Revised (Fraley, Waller, \& Brennan, 2000); ECR-RS = Relationship Structures questionnaire of the ECR-R. Correlations $>1.091$ are statistically significant. 
anxiety (averaged across relationship domains) and neuroticism was $.11(z=5.23, p<.05)$. Moreover, the correlation between ECR-R avoidance and agreeableness was -.35 , whereas the correlation between ECR-RS avoidance (averaged across relationship domains) and agreeableness was $-.23(z=2.58, p<.05)$. This indicates that less specific attachment measures, such as the ECR-R, are more likely to correlate with broader, trait-like measures of personality.

Differentiation. Given that the ECR-RS is designed to assess attachment across multiple domains, it provides an opportunity to investigate individual differences in differentiation in people's working models. Psychologists have proposed a number of ways to assess differentiation (e.g., Donahue et al., 1993). In this article, we adopt a method advocated by Baird, Le, and Lucas (2006). This method involves computing the standard deviation of items across different contexts. The logic is as follows: If a person behaves in similar ways across distinct contexts, then he or she should have similar scores across these contexts, resulting in a low withinperson standard deviation for the items in question. In contrast, if a person is highly differentiated in his or her behavior, there will be more variability in the way the person responds to an item in different contexts, leading to a larger within-person standard deviation for scores on that item across contexts.

Following the method described by Baird et al. (2006), for each participant, we computed nine standard deviations, one for each ECR-RS item (i.e., each person rated the same item in four contexts-for relationships with mother, father, partner, and friend). We then averaged those nine standard deviations to index the amount of differentiation the person exhibited in his or her working models. The average amount of differentiation observed in our sample was $1.26(S D=0.59)$, suggesting that, on average, people were relatively homogeneous in their attachment representations, varying in their responses to the attachment items by only 1.26 scale points, on average, across the four domains. Table 7 shows how this measure of differentiation was related to relationship functioning, depressive symptoms, and the Big Five personality traits (see the column labeled $S D$ ). In general, people who were more differentiated were less likely to report satisfaction in their romantic relationships $(r=-.14)$ and had higher levels of depression $(r=.27)$. They also reported greater levels of neurot$\operatorname{icism}(r=.21)$ and less agreeableness $(r=-.27)$.

As revealed in Table 7, differentiation is related to attachment insecurity itself. In other words, people who exhibited more differentiation tended to be more insecure as a general rule (i.e., averaging across relational domains). Indeed, Baird et al. (2006) argued that measures of differentiation are often confounded with trait or mean level. This confounding can emerge when item responses are skewed because, at the extreme end of a dimension, there is less room for variation in people's responses. To control for this problem, Baird et al. (2006) recommend computing residual scores in which people's $S D$ s are regressed on both the average item mean and the square of that mean. This adjusted index (adjusted standard deviation) represents the amount of differentiation that exists independently of whether a person generally tends to be secure or insecure. Table 7 shows the relationship between the adjusted standard deviation and the various variables of interest (see the column labeled Adjusted $S D$ ). What is noteworthy about these data is that there do not appear to be any associations between attachment differentiation and measures of inter- and
Table 7

Correlations Between Two Measures of Differentiation and the Big Five Personality Traits, Investment Model Scales, Depression, and Relationship Structures Scales

\begin{tabular}{|c|c|c|}
\hline \multirow[b]{2}{*}{ Scale } & \multicolumn{2}{|c|}{ Differentiation } \\
\hline & $S D$ & Adjusted $S D$ \\
\hline \multicolumn{3}{|l|}{ Big Five } \\
\hline Extraversion & -.17 & .09 \\
\hline Agreeableness & -.27 & .10 \\
\hline Neuroticism & .21 & .06 \\
\hline Conscientiousness & -.22 & .04 \\
\hline Openness & .02 & .11 \\
\hline \multicolumn{3}{|l|}{ Investment Model } \\
\hline Commitment & -.10 & -.01 \\
\hline Satisfaction & -.14 & .06 \\
\hline Alternatives & .06 & -.03 \\
\hline Investment & -.02 & -.08 \\
\hline \multicolumn{3}{|l|}{ Depression } \\
\hline CES-D & .27 & .03 \\
\hline \multicolumn{3}{|l|}{ ECR-RS } \\
\hline \multicolumn{3}{|l|}{ Anxiety } \\
\hline Mother & .41 & -.03 \\
\hline Father & .53 & .06 \\
\hline Partner & .32 & -.07 \\
\hline Friend & .38 & -.17 \\
\hline Global & .63 & -.08 \\
\hline \multicolumn{3}{|l|}{ Avoidance } \\
\hline Mother & .56 & -.02 \\
\hline Father & .73 & .19 \\
\hline Partner & .18 & -.19 \\
\hline Friend & .31 & -.30 \\
\hline Global & .74 & -.06 \\
\hline \multicolumn{3}{|l|}{ ECR-R } \\
\hline Anxiety & .27 & -.06 \\
\hline Avoidance & .22 & -.08 \\
\hline
\end{tabular}

Note. CES-D = Center for Epidemiologic Studies-Depression scale (Kohout, Berkman, Evans, \& Cornoni-Huntley, 1993); ECR-R = Experiences in Close Relationships-Revised (Fraley, Waller, \& Brennan, 2000); ECR-RS $=$ Relationship Structures questionnaire of the ECR-R. Correlations $>1.09 \mid$ are statistically significant.

intrapersonal functioning once average levels of anxiety and avoidance are taken into account. This is compatible with what Baird et al. (2006) found in predicting well-being from adjusted measures of personality differentiation. They found that people with highly differentiated personalities tended to report less wellbeing but that this relationship disappeared when the correlation between overall trait levels and variability were taken into consideration.

In short, it appears that attachment differentiation is negatively related to intra- and interpersonal measures of adjustment but that this association is mostly due to the fact that highly differentiated people tend to be more insecure on average. Once we controlled for overall levels of security, the association between differentiation in working models and adjustment largely disappeared.

\section{General Discussion}

A primary goal of this article was to present a self-report method that would address four limitations of commonly used attachment measures. First, we wanted to develop a measure that clearly 
specified the target being rated so there is no ambiguity in whether participants were rating their current partners, romantic partners in general, or people to whom they feel close (romantic or otherwise). Second, we sought to develop a measure with items that were not specific to one kind of relational domain (e.g., romantic) so that scores across relationship domains could be compared on a common metric. Third, we wanted a measure that was relatively short so that attachment could be assessed across relationship domains without placing an unnecessary burden on clients or research participants. Finally, we desired a measure that could be used to study not only security versus insecurity in different relational domains but also the amount of homogeneity versus differentiation that exists in people's working models.

The Relationship Structures (ECR-RS) questionnaire helps to address these issues. The ECR-RS can be used to assess attachment-related anxiety and avoidance in people's relationships with their mothers, fathers, partners, and friends. Because a common set of items is used to assess attachment in different domains, security across contexts can be contrasted and compared in meaningful ways.

In Study 1, we demonstrated that the two-dimensional structure familiar to contemporary attachment researchers emerged in each of the four relational domains of interest. Moreover, the composite scores we created for anxiety and avoidance in each relational domain were highly reliable $(\alpha s>.80)$, despite being based on a small number of items. We also found that the correlations between the attachment dimensions across relational domains were relatively modest, corroborating previous research published by Baldwin et al. (1996) and Klohnen et al. (2005). This has a number of implications for research and theory on adult attachment. For one, it indicates that the common trait-like approach to assessing attachment, although valuable in its own right, might not allow the nuances of attachment across contexts to be assessed adequately. If researchers are primarily interested in studying attachment in romantic relationships, it might be advisable for them to assess individual differences in that domain specifically rather than to assume that a more global or less specific measure captures the variance of interest. Another implication of these data, most clearly revealed in Study 2, is that it is possible to show the association between attachment and various outcomes with higher fidelity when context is taken into consideration. For example, as shown in Table 5, attachment-related anxiety and avoidance, as assessed in the context of a romantic relationship, are more strongly correlated with satisfaction, investment, and commitment than the measures of attachment taken in the parental or friend domains. The consideration of context also reveals that the strength of the associations between the Big Five personality traits, and the attachment dimensions is much weaker when attachment is assessed in a context-specific manner than when it is assessed in a more general fashion (e.g., via the ECR-R). This suggests that the association that exists between measures of adult attachment and basic personality traits (Noftle \& Shaver, 2006) might exist primarily for broader, decontextualized assessments of attachment.

We also examined the extent to which differentiation in working models (i.e., the extent to which people have a relatively homogeneous vs. heterogeneous set of attachment representations across relationship domains) is related to inter- and intrapersonal outcomes. Our analyses indicated that, although highly differentiated people were less likely to be satisfied in their relationships and more depressed, this association was largely due to the fact that highly differentiated people tend to be more insecure, on average. Once we controlled for insecurity (see Baird et al., 2006), the association between differentiation and these various outcomes all but disappeared. This finding implies that, at least with respect to the variables we assessed, there may not be any unique implications of heterogeneity in working models per se. Someone who has relatively secure representations of his or her romantic partner but insecure working models with respect to his or her parents is not going to have less satisfying relationships or experience more depression because of the lack of congruity in attachment representations across domains. Those relationships might be less satisfying, however, because the insecure representations contribute to an overall weaker propensity to function well in interpersonal and intrapersonal domains.

\section{Limitations, Caveats, and Conclusions}

Although the ECR-RS has the potential to be useful, it would be premature to claim that it is without limitations. One noteworthy limitation of the measure is that the items are not well balanced with respect to keying. None of the items designed to assess attachment-related anxiety, for example, are keyed in the opposite direction. As such, like other measures of attachment that have this problem, the ECR-RS anxiety scales have the potential to suffer from response acquiescence.

A second problem is that the ECR-RS does not address an issue identified, but not resolved, by Fraley et al. (2000) concerning self-report measures of attachment. Most attachment measures tend to be good at differentiating among people on the insecure end of the spectrum but are relatively poor at differentiating people on the secure end. As an analogy, most self-report measures function in the same way that algebra-focused math tests might function. These tests can differentiate people with poor math skills fairly well, but they cannot differentiate people with basic knowledge in calculus from people with advanced training in differential equations and matrix algebra. This issue is a potential concern for researchers who use the ECR-RS or any other self-report measure of attachment (see Fraley et al., 2000) because people tend to be relatively secure on average. As such, the majority of the people being assessed will be assessed with less fidelity than the minority of the people scoring on the insecure ends of the ECR-RS dimensions. Future research should focus on developing items that allow highly secure people to be discriminated from one another with greater precision.

In this article we have presented the ECR-RS questionnaire as a means to assess attachment in specific contexts: parental, romantic, and platonic friendships. However, the ECR-RS was not intended to be limited to these domains in particular. In fact, it was designed specifically to be flexible in its use. Conceptually, the ECR-RS items could be used to assess attachment in other domains as well, such as sibling relationships (Tancredy \& Fraley, 2006), relationships to God (Kirkpatrick, 1998), relationships to pets (Kurdek, 2009), or relationships to teachers or counselors (Meyer \& Pilkonis, 2001). Moreover, there is no reason why an investigator should only use four domains, as we have done in our work here. Obviously, the more interested the researcher is in making distinctions among global versus specific attachment rep- 
resentations, the more value there is in using multiple relational domains.

Beyond the ECR-RS itself, there are also some limitations of these particular studies and samples. For one, we have a high proportion of women participating in our web-based research. It is generally argued that women are more interdependent and concerned with close relationships compared with men (Cross \& Madson, 1997), which raises important questions about whether the men in our sample are representative of men more generally. Although we did not observe large sex differences in our data, it is important to keep in mind that our sample might not capture the full range of psychological variation of interest. We also included highly limited demographic assessments. For example, we did not assess whether participants came from intact families, how much interaction they had with their best friends, or other variables that would be relevant for understanding each of these relational domains in a more nuanced fashion.

Another potential limitation is the moderate to high correlation we observed between attachment-related anxiety and avoidance, both at the level of relationship-specific scales (e.g., mother) and the more global scales. Although it is often assumed by researchers that these dimensions should be uncorrelated (see Mikulincer, Shaver, Sapir-Lavid, \& Avihou-Kanza, 2009), we would argue that this assumption might be too strong. The two dimensions are clearly separable and conceptually independent (e.g., see Bartholomew, 1990); the insecurity that a person experiences regarding attachment figures is not the same conceptual "thing" as the strategies he or she uses to regulate his or her affect and behavior (see Fraley \& Shaver, 2000). But conceptually distinct things need not be statistically independent. It might be helpful to consider a related example: satisfaction and investment. Relationship scholars have traditionally treated investment and satisfaction as distinct concepts for a number of reasons, including the fact that a person can be deeply invested in his or her relationship but unsatisfied with it (Rusbult et al., 1998). Despite this conceptual independence, measures of satisfaction and investment tend to correlate relatively strongly with one another ( $r=.34$ in our Study 2). People who are satisfied in their relationships also tend to be highly invested in them. Although the high correlation among these measures can provide a basis for aggregating them for convenience in some research contexts, the correlation does not imply that they are identical constructs, nor does it imply that the constructs are being measured inadequately.

In short, from a theoretical point of view, we do not think that there is any reason to assume that anxiety and avoidance should be uncorrelated with one another. Indeed, recent meta-analytic research shows that they tend to correlate about .20 in samples using the ECR or the ECR-R and that the correlation is even stronger in samples using the ECR-R or people in committed relationships (see Finnegan \& Cameron, 2009). But the fact that there is a correlation between the scales makes it important that researchers study the independent contributions of the dimensions to outcomes of interest, something that is easy to do via multiple regression and other statistical techniques. We have not done so here largely because of the large number of analyses presented and because we did not have specific hypotheses about the independent contribution that the two dimensions might make to specific outcomes. But if researchers are specifically interested in, for example, the contribution of attachment-related avoidance to a specific outcome, it would be wise to control for attachment-related anxiety (or simultaneously estimate its coefficient) in the process.

Finally, we would like to note that psychological measurement should be viewed as an evolutionary process. We do not consider the ECR-RS to be a final or flawless product. As we noted in the introduction, many researchers are already attempting to address more contextualized questions about attachment (e.g., Brumbaugh \& Fraley, 2007; Cozzarelli, Hoekstra, \& Bylsma, 2000; Fraley, 2007; Klohnen et al., 2005). However, because there is no commonly established method for doing so, many of these efforts have been ad hoc and have relied on different questionnaires; different item sets; different instructions; and, in some cases, different conceptual models of individual differences in attachment. We believe there is some value in building upon existing, widely used measures and models to assess attachment in context. Our hope is that the ECR-RS, being derived from a commonly used "global" measure (i.e., the ECR-R), will provide a useful way of creating continuity between investigations that focus more on trait-like investigations of attachment and investigations designed to focus on specific relationships or study attachment across multiple contexts. We are continuing to work on ways to improve measurement and we encourage others to do so as well.

In closing, we hope this research will help advance the study of adult attachment by providing a short and useful method for assessing individual differences in attachment across multiple contexts. Although several researchers have drawn attention to interesting questions about attachment in multiple domains, we suspect that one reason such research is uncommon is the lack of a standard way to assess attachment in different contexts. We hope that the ECR-RS will provide a useful common ground for researchers and practitioners interested in such issues.

\section{References}

Armsden, G. C., \& Greenberg, M. T. (1987). The Inventory of Parent and Peer Attachment: Individual differences and their relationship to psychological well-being in adolescence. Journal of Youth and Adolescence, 16, 427-454. doi:10.1007/BF02202939

Baird, B. M., Le, K., \& Lucas, R. E. (2006). On the nature of intraindividual personality variability: Reliability, validity, and associations with well-being. Journal of Personality and Social Psychology, 90, 512-527. doi:10.1037/0022-3514.90.3.512

Baldwin, M. W., Keelan, J. P. R., Fehr, B., Enns, V., \& Kohs-Rangarajoo, E. (1996). Social-cognitive conceptualizations of attachment working models: Availability and accessibility effects. Journal of Personality and Social Psychology, 71, 94-109. doi:10.1037/0022-3514.71.1.94

Bartholomew, K. (1990). Adult avoidance of intimacy: An attachment perspective. Journal of Social and Personal Relationships, 7, 147-178.

Bowlby, J. (1969). Attachment and loss: Vol. 1. Attachment. New York, NY: Basic Books.

Brennan, K. A., Clark, C. L., \& Shaver, P. R. (1998). Self-report measurement of adult attachment: An integrative overview. In J. A. Simpson \& W. S. Rholes (Eds.), Attachment theory and close relationships (pp. 46-76). New York, NY: Guilford Press.

Brumbaugh, C. C., \& Fraley, R. C. (2007). The transference of attachment patterns: How parental and romantic relationships influence feelings toward novel people. Personal Relationships, 14, 513-530. doi:10.1111/ j.1475-6811.2007.00169.x

Buist, K. L., Reitz, E., \& Dekovíc, M. (2008). Attachment stability and change during adolescence: A longitudinal application of the social relations model. Journal of Social and Personal Relationships, 25, 429-444. doi:10.1177/0265407508090867 
Cassidy, J., \& Shaver, P. R. (Eds.). (2008). Handbook of attachment: Theory, research, and clinical applications (2nd ed.). New York, NY: Guilford Press.

Collins, N. L., \& Read, S. J. (1990). Adult attachment, working models, and relationship quality in dating couples. Journal of Personality and Social Psychology, 58, 644-663. doi:10.1037/0022-3514.58.4.644

Cook, W. L. (2000). Understanding attachment security in family context. Journal of Personality and Social Psychology, 78, 285-294. doi: 10.1037/0022-3514.78.2.285

Cozzarelli, C., Hoekstra, S. J., \& Bylsma, W. H. (2000). General versus specific mental models of attachment: Are they associated with different outcomes? Personality and Social Psychology Bulletin, 26, 605-618. doi: $10.1177 / 0146167200267008$

Cross, S. E., \& Madson, L. (1997). Models of the self: Self-construals and gender. Psychological Bulletin, 122, 5-37. doi:10.1037/00332909.122.1.5

Donahue, E. M., Robins, R. W., Roberts, B. W., \& John, O. P. (1993). The divided self: Concurrent and longitudinal effects of psychological adjustment and social roles on self-concept differentiation. Journal of Personality and Social Psychology, 64, 834-846. doi:10.1037/00223514.64.5.834

Figueiredo, B., Field, T., Diego, M., Hernandez-Reif, M., Deeds, O., \& Ascencio, A. (2008). Partner relationships during the transition to parenthood. Journal of Reproductive and Infant Psychology, 26, 99-107. doi:10.1080/02646830701873057

Finnegan, H., \& Cameron, J. J. (2009, February). Orthogonal dreams in an oblique world: A meta-analysis of the relation between anxiety and avoidance in the ECR and ECR-R. Poster presented at the 10th annual meeting for the Society of Personality and Social Psychology, Tampa, FL.

Fraley, R. C. (2007). A connectionist approach to the organization and continuity of working models of attachment. Journal of Personality, 75, 1157-1180. doi:10.1111/j.1467-6494.2007.00471.x

Fraley, R. C., \& Shaver, P. R. (2000). Adult romantic attachment: Theoretical developments, emerging controversies, and unanswered questions. Review of General Psychology, 4, 132-154.

Fraley, R. C., Waller, N. G., \& Brennan, K. A. (2000). An item response theory analysis of self-report measures of adult attachment. Journal of Personality and Social Psychology, 78, 350-365. doi:10.1037/00223514.78.2.350

Gosling, S. D., Vazire, S., Srivastava, S., \& John, O. P. (2004). Should we trust Web-based studies? A comparative analysis of six preconceptions about Internet questionnaires. American Psychologist, 59, 93-104. doi: 10.1037/0003-066X.59.2.93

Hazan, C., \& Shaver, P. (1987). Romantic love conceptualized as an attachment process. Journal of Personality and Social Psychology, 52, 511-524. doi:10.1037/0022-3514.52.3.511

John, O. P., \& Srivastava, S. (1999). The Big Five trait taxonomy: History, measurement, and theoretical perspectives. In L. A. Pervin \& O. P. John (Eds.), Handbook of personality: Theory and research, 2nd ed. (pp. 102-138). New York, NY: Guilford Press.

Kirkpatrick, L. A. (1998). Evolution, pair-bonding, and reproductive strategies: A reconceptualization of adult attachment. In J. A. Simpson \& W. S. Rholes (Eds.), Attachment theory and close relationships (pp. 353-393). New York, NY: Guilford Press.

Klohnen, E. C., Weller, J. A., Luo, S., \& Choe, M. (2005). Organization and predictive power of general and relationship-specific attachment models: One for all, and all for one? Personality and Social Psychology Bulletin, 31, 1665-1682. doi:10.1177/0146167205278307

Kohout, F. J., Berkman, L. F., Evans, D. A., \& Cornoni-Huntley, J. (1993). Two shorter forms of the CES-D Depression Symptoms Index. Journal of Aging and Health, 5, 179-193. doi:10.1177/089826439300500202

Kurdek, L. A. (2009). Pet dogs as attachment figures for adult owners. Journal of Family Psychology, 23, 439-446. doi:10.1037/a0014979

La Guardia, J. G., Ryan, R. M., Couchman, C. E., \& Deci, E. L. (2000). Within-person variation in security of attachment: A self-determination theory perspective on attachment, need fulfillment, and well-being. Journal of Personality and Social Psychology, 79, 367-384. doi: 10.1037/0022-3514.79.3.367

Lo, C., Walsh, A., Mikulincer, M., Gagliese, L., Zimmermann, C., \& Rodin, G. (2009). Measuring attachment security in patients with advanced cancer: Psychometric properties of a modified and brief Experiences in Close Relationships Scale. Psycho-Oncology, 18, 490-499. doi:10.1002/pon.1417

Meyer, B., \& Pilkonis, P. A. (2001). Attachment style. Psychotherapy: Theory, Research, Practice, Training, 38, 466-472. doi:10.1037/00333204.38.4.466

Mikulincer, M., Shaver, P. R., Sapir-Lavid, Y., \& Avihou-Kanza, N (2009). What's inside the minds of securely and insecurely attached people? The secure-base script and its associations with attachment-style dimensions. Journal of Personality and Social Psychology, 97, 615633. doi: $10.1037 / \mathrm{a} 0015649$

Noftle, E. E., \& Shaver, P. R. (2006). Attachment dimensions and the Big Five personality traits: Associations and comparative ability to predict relationship quality. Journal of Research in Personality, 40, 179-208. doi:10.1016/j.jrp.2004.11.003

Overall, N. C., Fletcher, G. J. O., \& Friesen, M. D. (2003). Mapping the intimate relationship mind: Comparisons between three models of attachment representations. Personality and Social Psychology Bulletin, 29, 1479-1493. doi:10.1177/0146167203251519

Rusbult, C. E., Martz, J. M., \& Agnew, C. R. (1998). The Investment Model Scale: Measuring commitment level, satisfaction level, quality of alternatives, and investment size. Personal Relationships, 5, 357-387. doi:10.1111/j.1475-6811.1998.tb00177.x

Schmitt, D. P., \& the International Sexuality Description Project. (2003). Are men universally more dismissing than women? Gender differences in romantic attachment across 62 cultural regions. Personal Relationships, 10, 307-331. doi:10.1111/1475-6811.00052

Tancredy, C. M., \& Fraley, R. C. (2006). The nature of adult twin relationships: An attachment-theoretical perspective. Journal of Personality and Social Psychology, 90, 78-93. doi:10.1037/0022-3514.90.1.78

Wei, M., Russell, D. W., Mallinckrodt, B., \& Vogel, D. L. (2007). The Experiences in Close Relationship Scale (ECR)-Short Form: Reliability, validity, and factor structure. Journal of Personality Assessment, 88, 187-204.

Zayas, V., Shoda, Y., Mischel, W., Osterhout, L., \& Takahashi, M. (2009). Neural responses to partner rejection cues. Psychological Science, 20 813-821. doi:10.1111/j.1467-9280.2009.02373.x

Received August 19, 2010

Revision received December 29, 2010 Accepted December 30, 2010 